Monleón Pradas, Mau.

Profesora Titular, Universidad Politécnica de Valencia, Departamento de Escultura, Laboratorio de Creaciones Intermedia (LCI).

\title{
La creación audiovisual como herramienta educativa frente a la desigualdad entre los sexos en el proyecto Nosotr@s hablamos.
}

\author{
TIPO DE TRABAJO \\ Comunicación. \\ PALABRAS CLAVE \\ Feminismo, video-creación, violencia de género estructural y simbólica, pedagogía.
}

KEY WORDS:

Feminism, video-creation, structural and symbolic gender violence, education.

RESUMEN

Esta comunicación parte de un proyecto de investigación que toma la creación audiovisual como medio para superar las desigualdades de género en nuestra sociedad actual. En este sentido, el proyecto Nosotr@s hablamos. Superando discriminaciones en la adolescencia, que consiste en un audiovisual y una guía didáctica, será expuesto y analizado con el objetivo de demostrar el poder pedagógico de la creación audiovisual, así como la capacidad emancipatoria del análisis y la praxis feminista.

Todo proyecto de emancipación contemporáneo precisa, recordamos a Marcuse, una revolución científica y técnica anterior. Toda propuesta efectiva de emancipación a través de la tecnología ha de pasar por estrategias de infiltración.

En el proyecto Nosotr@s hablamos se reivindica la presencia de la mujer no sólo como usuaria de tecnología sino, de manera especial, como participante activa en las políticas de producción y distribución del material audiovisual y en las políticas sociales y educativas vinculadas a la tecnología. Desde la video-creación se plantean varios desafíos a este respecto, indudablemente las políticas contra la "tecnofobia femenina" y la promoción de la presencia de mujeres en los estudios científico-técnicos serán asuntos cruciales.

El poder del lenguaje audiovisual en la creación y el cuestionamiento de los imaginarios culturales nos lleva en un primer momento a considerarlo como un medio propicio para la producción de nuevas formas de subjetividad y para la lucha por la igualdad. Las políticas de la identidad, en la era post-corpórea, serían en este sentido asunto crucial que quedan cuestionadas desde el feminismo. La desigualdad de género reflejada en los medios de masas y en la propia realidad social serán cuestionadas a través de la video-creación, fomentando una pedagogía de la imagen que supere la violencia de género estructural y simbólica.

\section{ABSTRACT}

This communication goes on of a research project that takes the audiovisual creation as a means to overcome gender inequalities in our society. In this sense, the Project called Nosotr@s hablamos. Superando discriminaciones en la adolescencia, which is an audiovisual and a tutorial, will be exposed and analyzed in order to demonstrate the pedagogical power of audiovisual creation and the emancipatory capacity of the feminist analysis and praxis. 
Any project of contemporary emancipation precises, like Marcuse remembers to us, an earlier scientific and technical revolution. Any effective proposal of emancipation through technology strategies must pass through infiltration.

In the Project Nosotr@s hablamos, we claimed the presence of women not only as a user of technology but, especially, as an active participant in the policies of production and distribution of audio-visual material and social and educational policies related to technology. Trough the video-creation we asume several challenges, and in this regard undoubtedly policies against "feminine technophobia", and we also promote the presence of women in scientific and technical studies that will be crucial issues to arise.

The power of visual language in creating and questioning cultural imaginary leads at first to regard it as an enabling environment for the production of new forms of subjectivity and for the fight for equality. The politics of identity in the post-corporeal era are crucial subjects to be challenged in this regard from a feminist persepective. Gender inequality reflected in the mass media and the social reality will be challenged through the video-creation, fostering a pedagogy of the image that exceeds the structural and symbolic violence of gender.

\section{CONTENIDO}

\section{INTRODUCCIÓN}

El proyecto Nosotr@s hablamos. Superando discriminaciones en la adolescencia ${ }^{1}$, ha sido publicado por la Universidad de Valencia y auspiciado por el Instituto de la Mujer. En él se ponen de manifiesto los efectos que las idealizaciones y prescripciones culturales en torno al sexo producen en la construcción de la subjetividad, así como los usos y abusos mediáticos en la representación de las mujeres y de la violencia que se ejerce contra ellas. La carga de violencia simbólica que subyace a la subjetividad femenina se encubre bajo formas benévolas de sexismo transmitidas en el imaginario colectivo, y está presente en la dificultad para percibir la asimetría de las relaciones entre los sexos y detectar formas sutiles de violencia. Partimos del supuesto de que la conceptuación de la violencia contra las mujeres en el ámbito educativo está impregnada de visiones y conocimientos provenientes, entre otros, de los medios, y que éstos han de someterse a consideración desde la docencia, desvelando los mitos, las creencias estereotipadas, así como las tensiones y asimetrías que subyacen a los modelos normativos de género.

El material Nosotr@s hablamos. Superando discriminaciones en la adolescencia, se estructura a través de dos grandes ejes conceptuales: el primero es el material audiovisual de video-creación ${ }^{2}$, que nos ha servido de soporte para el registro y posterior análisis cualitativo del discurso adolescente, facilitando el diseño de una experiencia educativa que fomente la igualdad, sensibilice y prevenga contra la violencia. El segundo eje se articula en torno a la guía didáctica, estructurada en relación a la producción audiovisual a través de tres partes fundamentales, que se repiten para cada uno de los capítulos del vídeo, y que constituyen: el marco teórico, la parte testimonial de los y las adolescentes en: Nosotr@s hablamos, y finalmente las actividades propuestas en relación a los apartados anteriores.

En nuestra comunicación titulada La creación audiovisual como herramienta educativa frente a la desigualdad entre los sexos en el proyecto Nosotr@s hablamos, profundizaremos especialmente en los cimientos teóricos que sustentan el material audiovisual de videocreación, pues nos interesa destacar los mecanismos por los que este material puede convertirse en recurso educativo en nuestra era post-corpórea, cuestionando las políticas de la identidad desde la teoría y la praxis feminista. Nuestra disertación parte de

\footnotetext{
${ }^{1}$ Se trata de una propuesta educativa que surge como continuación de investigaciones anteriores, realizadas en el marco de sucesivas convocatorias del Plan Nacional de Investigación I+D+I, Programa Sectorial de Estudios de las mujeres y del género. La publicación Nosotr@s hablamos. Superando discriminaciones en la adolescencia, UV, (2011) de las autoras: Amparo Bonilla Campos, Isabel Martínez Benlloch, Mau Monleón Pradas y Cristina Vega Solís, con la colaboración especial de Jennifer Tapias Derch se enmarca en la investigación "Superando discriminaciones y violencias: propuesta participativa para la igualdad entre los sexos en la adolescencia". Este estudio fue financiado por el Instituto de la Mujer en el marco: Proyectos de Investigación del Plan Nacional I+D+I. Programa: Acción estratégica sobre el fomento de igualdad de oportunidades entre hombres y mujeres. Proyecto 151/07. Ha colaborado el Laboratorio de ${ }^{2}$ Material Audiovisual: DVD, 30 min. Han intervenido como entrevistad@s: Aida Sandalinas; Álex Molina; Ángela Gadea; Andrea Salvador; Camila Tapias; Celia Uchina; Isaac Andujar; Isaac Folch; Ionut Néstor; Javier Ribes; Jorge Ferrando; Juli Luján; Liliya Ruseva; Laura Alemany; Luna Pérez; Luis Alberto; María Valero; Miguel José Torrent; Miriam Gonzalez; Nacho Saldías; Nacho Brines; Roxana Mazieu; Tirsa Molina. La estructura del guión ha sido realizada por: Isabel Martínez Benlloch, Amparo Bonilla Campos y Mau Monleón Pradas La dirección audiovisual corre a cargo de Mau Monleón, con la operadora de cámara y montaje Jennifer Tapias Derch. Han colaborado: Escola "La Florida". Catarroja (Valencia): Empar Martínez Bonafé y Merxe Sánchez; IES "Isabel de Villena". Valencia: Àngels Martínez Bonafé y Rosa Sanchìs.
} 
los presupuestos de este material audiovisual, donde se ha establecido una hipótesis que se sustenta en tres motivos fundamentales que dan lugar a los objetivos del proyecto:

-La existencia de un proceso de cambio en la concepción y representación de la violencia machista en el que juegan un papel destacado las culturas mediáticas, especialmente los medios de comunicación, y entre ellos la creación audiovisual.

-La preeminencia de éstos en los procesos de producción, circulación y recepción del conocimiento dentro y fuera del contexto educativo.

-La labilidad de la adolescencia frente a las prescripciones de género y el ajuste a las creencias y valores del grupo de pares.

Por lo tanto, nuestro objetivo principal al analizar este trabajo del que procede el presente material creativo, de carácter audiovisual, es el análisis de los mitos, creencias y prejuicios que en torno a la diferencia sexual interiorizan las y los adolescentes, y que, desde el imaginario cultural, justifican las asimetrías de poder entre los sexos. Asimismo, la tolerancia hacia formas encubiertas de violencia y la manifestación de actitudes y comportamientos a los que subyace discriminación, evidencian los mecanismos de invisibilización de la violencia simbólica, que muchas veces resulta más patente en sus efectos que en sus propias manifestaciones.

Las entrevistas directas son un buen instrumento para desvelar dichos mecanismos y, en la realización del vídeo, hemos utilizado testimonios de adolescentes de entre 15 y 19 años, intentando abarcar distintos grupos sociales, trabajando en centros educativos y con grupos y redes sociales que coexisten actualmente en la ciudad de Valencia. Nuestra intención ha sido en todo momento partir del protagonismo y la participación activa de est@s adolescentes.

De manera más concreta, los objetivos específicos que se han perseguido a lo largo de todo el proceso de conceptuación y realización del proyecto audiovisual -que se concreta en la propuesta educativa Nosotr@s hablamos-son, entre otros:

- Analizar y ayudar a cuestionar, a través de los testimonios de chicos y chicas, las creencias en torno a la amistad, el amor, las expectativas de futuro y la violencia contra las mujeres. Es decir, explorar las opiniones, actitudes y prácticas culturales y sociales que viven las y los jóvenes en su interrelación con personas de otro sexo.

- Analizar las actitudes, valores y creencias relacionadas con la violencia de género y plantear el debate acerca de cómo éstas inciden en la resolución de conflictos en el contexto educativo.

- Analizar las permanencias y rupturas de las prescripciones de género que inciden en la construcción de la subjetividad, y aportar elementos conceptuales para la intervención activa y superación de conflictos.

- Analizar los diversos discursos que hoy conforman, con enorme poder, el imaginario juvenil y, en concreto las representaciones sobre la violencia contra las mujeres, fundamentalmente a través de materiales provenientes de las culturas mediáticas (televisión, prensa juvenil y femenina, cine, publicidad, campañas de sensibilización, etc.) partiendo de una visión feminista crítica para iluminar el carácter marcadamente ideológico de estos discursos.

- Ofrecer materiales para la implementación de experiencias educativas participativas para la formación en la igualdad entre los sexos y visibilizar la violencia simbólica.

El material audiovisual que aquí se presenta se encamina pues a promover la igualdad entre los sexos en la adolescencia, desde una perspectiva de la acción educativa y la intervención social que tenga en cuenta la visión y los intereses de cada uno de los sujetos que intervendrán en el proceso de utilización de la guía didáctica y en particular el colectivo al que va dirigida. Presentamos un material integrado e interdisciplinario, fruto de la labor conjunta de investigadoras en el campo de la psicología, la sociología, el arte y el lenguaje audiovisual.

\section{¿POR QUÉ UN AUDIOVISUAL COMO HERRAMIENTA EDUCATIVA FRENTE A LA DESIGUALDAD ENTRE LOS SEXOS?}

Actualmente la propia idea de violencia se ha ampliado hasta recoger comportamientos que estaban invisibilizados o considerados socialmente aceptables. Entre ellos, el acoso psicológico y las actitudes de desprecio dentro y fuera de la pareja y/o el hogar, pero también, y esto es una novedad más reciente, la violencia que se ejerce desde las representaciones culturales o, en un sentido más amplio, desde la comunicación y las industrias mediáticas ${ }^{3}$ : cine, publicidad, campañas públicas, prensa, etc. En este sentido existen estudios referenciales precedentes y contemporáneos a nuestro trabajo, que han surgido en la mayoría de los casos en contextos universitarios, y que desde una perspectiva de la praxis y la teoría feminista han intentado dar respuesta a las problemáticas relacionadas con la reivindicación de la igualdad entre los sexos (Villaplana y Sichel, 2005; Vega, 2005). De este modo, a la labor que ya se venía realizando en el terreno educativo, se ha sumado una incipiente intervención en un campo cultural más complejo que hoy se sitúa en el centro de las pedagogías sociales.

\footnotetext{
${ }^{3}$ Ver, en este sentido, las definiciones y representaciones artísticas compiladas en la Plataforma de lucha contra la violencia de género ACVG, Directora MONLEÓN, Mau. Arte contra violencia de género. [En línea] [Octubre, 30, 2010] [Consultado mayo, 13, 2015] Disponible en internet en: www.artecontraviolenciadegenero.org
} 


\section{NOSOTR@S HABLAMOS: UNA APUESTA POR LA VIDEO-CREACIÓN. ¿QUIÉN, PARA QUÉ Y DESDE DÓNDE HABLAMOS?}

La video-creación se define como una pieza audiovisual artística, por lo general de corte no narrativo. En nuestro caso, hemos realizado un proyecto experimental en clave poética, que combina una base documental con crítica social, desde una perspectiva de género. De esta forma, hemos podido otorgar el protagonismo a los y las adolescentes a través de testimonios que se entretejen en un collage de imágenes entresacadas de los mas-media, el cine, la publicidad e internet, para dotar al conjunto de un sentido evocador abierto que más que afirmar, cuestiona desde la multiplicidad semántica y desde la interconexión entre voz e imagen. El audiovisual, de $30 \mathrm{~min}$ de duración, recoge las reflexiones de un total de 15 adolescentes entrevistad@s, intentando desvelar las creencias estereotipadas que aún hoy se mantienen en esta edad en torno a las posiciones sociales y subjetivas de chicas y chicos, y denunciar, al mismo tiempo, los efectos que produce la falta de educación en la igualdad. A través del análisis y contrapunto de sus propios discursos hemos querido crear nuevos marcos de análisis y reflexión que posibiliten la emergencia de alternativas de relación entre los sexos, apoyadas en cambios de mentalidad que, a su vez, incidirán en la subjetividad.

Para realizar las entrevistas hemos acudido en su mayoría a Institutos públicos de la ciudad de Valencia, donde a partir de un cuestionario tipo que pretende respuestas de valor cualitativo, hemos dejado libertad a @@s entrevistad@s para que nos expliquen sus puntos de vista, contradicciones, mandatos de género y roles adquiridos.

Las entrevistas nos han permitido aproximarnos a las creencias estereotipadas que se continúan manteniendo en la adolescencia en torno a la posición subjetiva de chicas y chicos y constatar los efectos que produce la falta de educación en la igualdad. También nos han permitido esbozar la creación de nuevos marcos de análisis y reflexión que posibiliten la emergencia de alternativas de relación entre los sexos, a partir de los propios intereses de chicas y chicos, de sus percepciones y valoraciones del imaginario cultural, de su posible cuestionamiento. De esta forma, las declaraciones de I@s adolescentes no afirman, sino que se abren al debate a través de su asociación con las imágenes de los mas-media, del cine, la prensa, etc. y junto con la estructura de preguntas que plantea el video desde una metodología socrática, asociada a la práctica feminista llamada "consciousness raising"4.

Estas metodologías nos han permitido trabajar con un tipo de material audiovisual que parte de distintos presupuestos y tiene una finalidad muy específica. En él se reivindica la presencia de la mujer no sólo como usuaria de tecnología sino, de manera especial, como participante activa en las políticas de producción y distribución del material audiovisual y en las políticas sociales y educativas vinculadas a la tecnología. Desde la video-creación se plantean varios desafíos a este respecto, indudablemente las políticas contra la "tecnofobia femenina" y la promoción de la presencia de mujeres en los estudios científico-técnicos ha sido una de nuestras metas a alcanzar, al tratarse de un equipo de mujeres de distintas disciplinas las que hemos abarcado tanto la realización del guión como la parte de la producción y postproducción de este material audiovisual.

Al mismo tiempo, dentro del porcentaje de adolescentes entrevistad@s, hemos seleccionado un total de más mujeres que hombres para la muestra definitiva; y ello por la necesidad de dar voz, desde la discriminación positiva, a aquellas que son invisibilizadas y en muchos casos menoscabadas en nuestra sociedad por el hecho de ser "jóvenes" y además "mujeres".

Por todo ello, respecto a la pregunta inicial del “¿quién, para qué y desde dónde hablamos?” podemos concluir que se ha se planteado una metodología de carácter dialéctico y feminista, de uso y reflexión académica, que pretende aportar una mirada crítica para la implementación de estrategias educativas que posibiliten dichas alternativas, desde la convicción de que los cambios de mentalidad incidirán en la subjetividad. Por ello se ha contado con el protagonismo de la comunidad adolescente a la que va dirigida de manera principal este proyecto.

\section{LA ESTRUCTURA DEL AUDIOVISUAL: CUESTIONANDO EL CUERPO, LA FAMILIA, EL AMOR Y LA SEXUALIDAD}

La estructura de nuestro material audiovisual, que se complementa perfectamente con la de la guía educativa, se organiza por tanto en los mismos capítulos. En la guía, cada uno estos capítulos está subdividido en dos apartados: en el primero se desarrollan los contenidos teóricos necesarios para la implementación de las actividades, contenidos que se presentan también, de forma resumida, al inicio del segundo apartado, dedicado a las distintas actividades propuestas. En este segundo apartado, para cada capítulo, se recogen articuladas las aportaciones de I@s adolescentes que aparecen en el audiovisual Nosotr@s hablamos para, finalmente, proponer todo un conjunto de tareas que abarcan la temática propuesta en el capítulo. De este modo, el visionado por capítulos del material audiovisual, permite el desarrollo y debate del marco teórico y la propuesta práctica la nuestra guía didáctica.

\footnotetext{
4 "Consciousness raising" o "awareness raising": la toma de conciencia (también llamado sensibilización), es una forma de activismo, popularizado en Estados Unidos por las mujeres feministas radicales a finales de los años 60'. A menudo toma la forma de un grupo de personas que tratan de centrar la atención de un grupo más amplio de personas en alguna causa o condición. En estos grupos se tratan problemáticas comunes que incluyen enfermedades (por ejemplo, cáncer de mama o el SIDA), los conflictos (por ejemplo, el genocidio de Darfur, el calentamiento global, los movimientos (por ejemplo, Greenpeace, PETA, La Hora del Planeta), y los partidos políticos o los políticos. Informar a la población de un interés público es a menudo considerado como el primer paso para cambiar la manera que manejan las instituciones.
} 
Esto es importante precisamente porque, el material audiovisual ha sido concebido de tal forma que puede visionarse y comprenderse de manera autónoma a la guía docente, y, sin embargo, se complementa perfectamente con ella a nivel estructural en la formación de los capítulos que configuran el guión de esta video-creación.

En definitiva, discurso audiovisual se ha estructurado en tres capítulos fundamentales (de unos 8 minutos de duración cada uno) y un epílogo (de unos 4 minutos).

El capítulo 1. el cuerpo. ¿Qué le exijo a mi cuerpo?, nos introduce en el análisis de las representaciones del cuerpo desde los mandatos de género. Para ello ha sido imprescindible abarcar la "significación de la diferencia sexual", reflexionando acerca de los efectos que nuestra condición de sujetos sexuados produce en la subjetividad, ya que nuestro cuerpo integra dimensiones del imaginario cultural y del orden simbólico que se manifiestan en cómo somos y cómo nos sentimos.
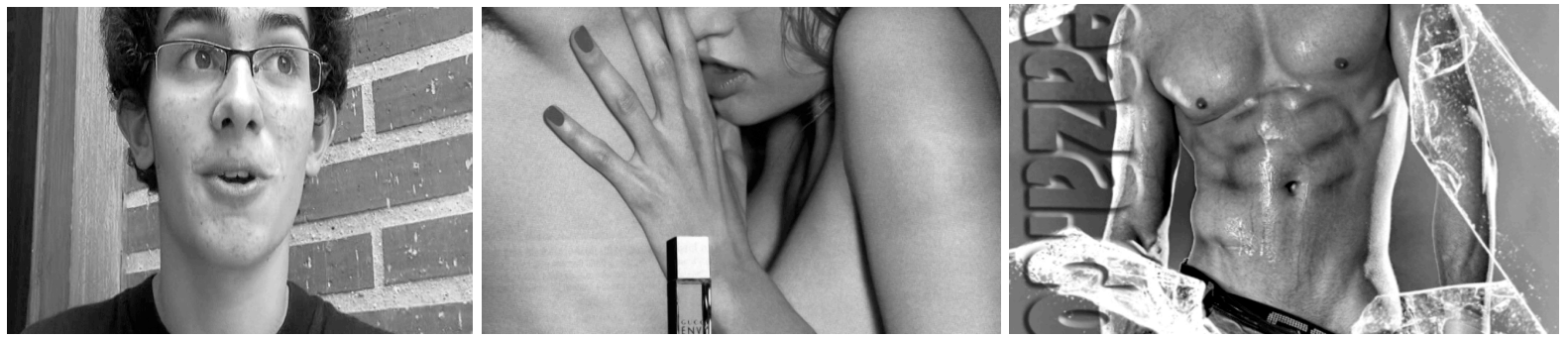

Fotogramas del video Nosotr@s hablamos

En cada cultura la diferencia sexual es la constante alrededor de la cual se organiza la sociedad. (...) La simbolización cultural de la diferencia anatómica toma forma en un conjunto de prácticas, ideas, discursos y representaciones sociales que dan atribuciones a la conducta objetiva y subjetiva de las personas en función de su sexo (Marta Lamas, 1995).

Actualmente, la representación del cuerpo, es decir la imagen corporal, ocupa cada vez más un lugar relevante en la interacción social. Los cuerpos, convertidos en iconos virtuales y hedonistas en la era post-corpórea, nos remiten a la pura apariencia, aparecen cosificados, sobre todo en el caso de las mujeres, y su significación es cada vez más compleja. Desvelar tópicos acerca de la naturaleza del cuerpo de las mujeres nos lleva a plantear las relaciones que subyacen al sistema sexo/género.

Las imágenes post-corpóreas como representaciones sociales del cuerpo e nuestra sociedad mediada por la tecnología así como los testimonios de I@s adolescentes nos aproximan al cuestionamiento de las demandas al propio cuerpo y de las exigencias que los y las adolescentes se ven forzados/as a cumplir, desde la presión de una sociedad mediática que estigmatiza a quien es diferente. El cuerpo se desvela como articulador de lo social y lo psíquico.

El capítulo 2. álbum de familia. ¿Cómo me marca la familia?, profundiza en la influencia que ejerce el núcleo familiar en las relaciones de pares, como ámbito primario de socialización y como entorno significativo en la adolescencia. Masculinidad y feminidad actualmente continúan viéndose como prototipos de expresión esencial que caracterizan básicamente a la persona y que se manifiestan en cualquier situación social por medio de actos rutinarios, especialmente en el ámbito familiar. El género además de ser considerado una identidad también es un rol, una puesta en escena.
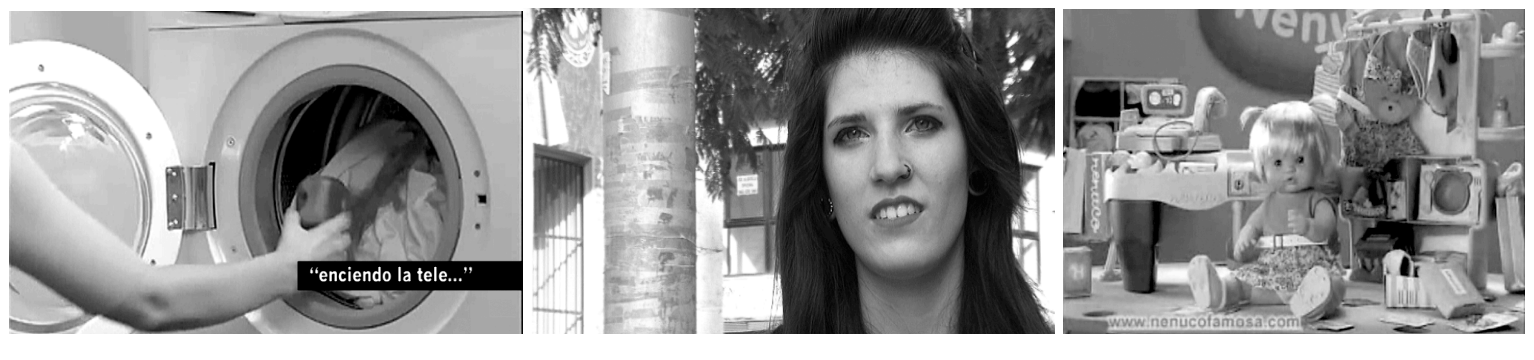

Fotogramas del video Nosotr@s hablamos

Desigualdad-discriminación-violencia forman parte de un particular circuito de realimentación mutua que se despliega a través de la producción social de las diversas formas de aceptación que legitiman tanto la desigualdad como las prácticas discriminatorias y, a la vez, invisibilizan los violentamientos. [...] Puede considerarse que los procesos de desigualdad-discriminación-violencia no son en rigor invisibles sino que están invisibilizados. [...] Se han invisibilizado en un complejo proceso socio-histórico (Eva Giberti y Ana Fernández, 1989). 
Para poder hacer visibles los discursos de poder y desigualdad sobre los que se asientan los roles, es necesario desagregar por sexo cualquier tipo de datos de información social y re-conceptuar a hombres y mujeres como grupos distintos, constituidos en relaciones psicosociales concretas e históricamente cambiantes, pero siempre asimétricas. Como afirma Bourdieu (2000), las estructuras de dominación son, además de históricas, resultado de un continuo trabajo de reproducción que se realiza a través de la violencia física y simbólica y en el que intervienen tanto agentes singulares como instituciones: Familia, Iglesia, Escuela, Estado.

Por ello ha sido preciso analizar los modos en que la ideología de género -el imaginario cultural en torno a la diferencia sexualse sigue transmitiendo -a pesar de la declaración de igualdad, los cambios en la estructura familiar y la generalización de la escuela mixta. Su relevancia en la propia construcción de la subjetividad y su incidencia en la violencia contra las mujeres -desde las formas sutiles y naturalizadas de violencia que producen y sustentan los modelos de género- obligan a tomar en consideración la cuestión de la legitimación que esta ideología encuentra en las representaciones de la masculinidad y la feminidad y en las relaciones entre mujeres y hombres en el imaginario cultural.

En este sentido, se han revisado los estereotipos o ideas preconcebidas que desdibujan los límites de la individualidad al unificar las características de las personas que constituyen una categoría y permitir homogeneizar a los individuos que pertenecen a ella. Los estereotipos justifican, de forma simplista, la naturaleza de las relaciones entre los grupos, ya que el conocimiento estereotipado -que tiene una fuerte carga emocional- filtra, de forma reduccionista, la realidad objetiva (Amparo Bonilla e Isabel Martínez Benlloch, 2000).

En este capítulo se enfatiza cómo el control ejercido por padres y madres sobre las chicas se traduce en estereotipos y se transfiere posteriormente a las relaciones con los chicos bajo la apariencia de protección. Para ello hemos utilizado apropiación de imágenes fílmicas y de diversas procedencias como prensa y televisión, así como las mencionadas entrevistas que estructuran todo el conjunto audiovisual.

El capítulo 3. amor y sexualidad. ¿Qué espero del/la otr@?, aborda el análisis de las posiciones subjetivas de chicas y chicos en un tema nuclear como son las relaciones sexuales y afectivas íntimas. La representación del "amor romántico" no sólo está condicionada por la cultura, sino que, a menudo, es un instrumento privilegiado de control que emana del orden social hegemónico, de manera que las relaciones de pareja son susceptibles de adolecer de las asimetrías de poder entre los sexos.

El amor es histórico y siempre es simbólico (...) Aprendemos ideologías amorosas, aprendemos los contenidos específicos del amor a través de mandatos, de normas, de creencias. Al vivir, cada persona trata de realizar el amor ideológicamente aprendido. En la realidad, la mayoría vive frustraciones amorosas porque casi nunca podemos realizar el imaginario amoroso al que estamos vinculadas (Marcela Lagarde, 2005).
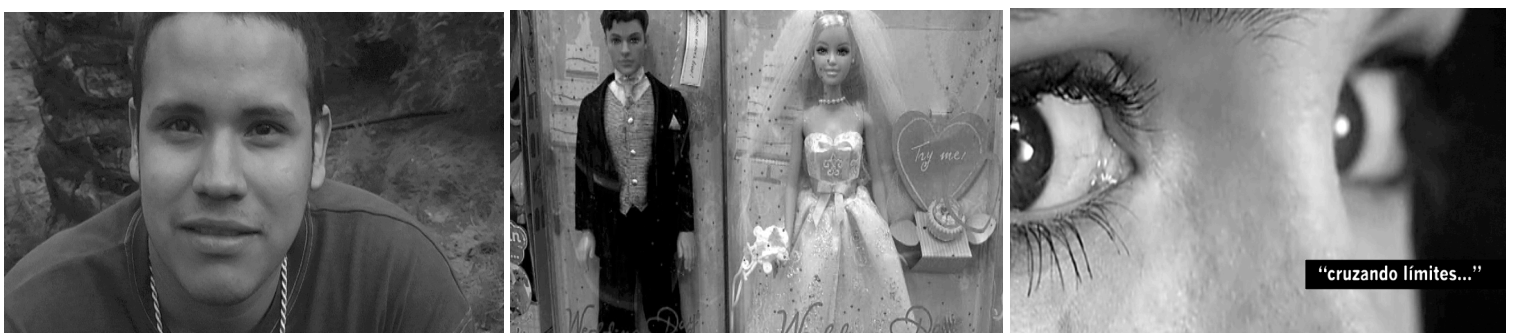

Fotogramas del video Nosotr@s hablamos

La sexualidad es también central en la vida de las personas y de las sociedades al actuar como eje de la organización social y delimitar espacios y condiciones de vida que influyen en los sentimientos, pensamientos y acciones humanas. Comprender la sexualidad como una producción social, y no como impulsos, supuso un punto de inflexión en las concepciones dominantes. Asimismo, las aportaciones de las teorías feministas con la introducción de nuevas categorías de análisis, como el concepto de género y su articulación con el cuerpo y la sexualidad, han contribuido a establecer un marco conceptual en el que ésta se incardina en un complejo proceso de construcción y producción socio-histórica, cultural, político y subjetivo (Lagarde, 1997, 2005; Carole Vance, 1984; Rubin, 1975). Pero los modelos sociales de conducta sexual no remiten a un simple sistema normativo que actúa desde fuera, sino que se inscriben en identidades a través de las cuales se opera el comportamiento y el control. Y en ello reside su enorme poder (Foucault, 1976).

Frente al paradigma esencialista que postula la existencia de una esencia compleja -interior e irreductible- que debe ser reprimida por la cultura a fin de encauzarla hacia el devenir prescrito, Weeks (1998), en su trabajo "la construcción cultural de las sexualidades. ¿Qué queremos decir cuando hablamos de cuerpo y sexualidad?", plantea que la sexualidad es una historia de prácticas sexuales (eróticas) cambiantes, de sistemas de regulaciones, definiciones sociales y significados subjetivos, así como de discursos, que sólo tienen en común el hecho de compartir la denominación. La sexualidad es una abstracción, una manera de conceptuar las experiencias en diversas potencialidades vitales, a saber: la de pertenecer a una especie sexuada y ser un sujeto generizado; la de experimentar placer 
erótico; la de procrear y la de desarrollar vínculos afectivos. Así, pues, constituye una categoría inestable y vital, producto de relaciones de poder.

Como se ha expuesto en los capítulos anteriores, las prácticas cotidianas están repletas de metáforas que aluden a mandatos y representaciones sociales. Éstos simbolizan la oposición y complementariedad hombre/mujer y se incorporan indistintamente en las subjetividades de mujeres y hombres (Norma Fuller, 1997), lo que significa que el sexismo no es patrimonio del sexo masculino. Además, las actitudes sexistas pueden dirigirse a los dos grupos sexuales, pero es evidente que el androcentrismo facilita que las valoraciones peyorativas se dirijan sobre todo al colectivo de mujeres, en general, como a aquellos varones con deseos homoeróticos -que traicionaron el genérico masculino al transgredir el orden "natural" de la sexualidad-o bien a aquellos más sensibles o "afeminados". La hegemonía heteronormativa establece así que la vivencia de la sexualidad sea asimétrica y se constituya en un espacio donde se escenifican y se reafirman desiguales posiciones de poder (Bourdieu, 2000; Robert Connell, 2002; Fuller, 1998; Tubert, 2001). Raquel Osborne (1993) afirma que sigue siendo difícil para muchas mujeres separar, en ciertos momentos, el amor de la sexualidad. A diferencia de lo que les pasa a los hombres que han aprendido a separar en exceso ambas esferas, a las mujeres se les ha hecho unirlas.

En este tercer capítulo audiovisual se subraya la importancia de la toma de decisiones sobre la vida sexual y amorosa durante la adolescencia, ya que contribuye al desarrollo de sujetos autónomos. El amor es una experiencia vitalizadora y, por ello, vale la pena invertir energía para aportar herramientas que potencien el amor, pero sin tener miedo a la separación cuando las relaciones no son saludables. Del mismo modo que en los capítulos anteriores hemos utilizado apropiación de imágenes fílmicas y de los medios de masas, así como las entrevistas a adolescentes para generar el este discurso crítico y en un montaje y collage que propone preguntas, debates y respuestas.

\section{EL EPÍLOGO. SUPERANDO DISCRIMINACIONES}
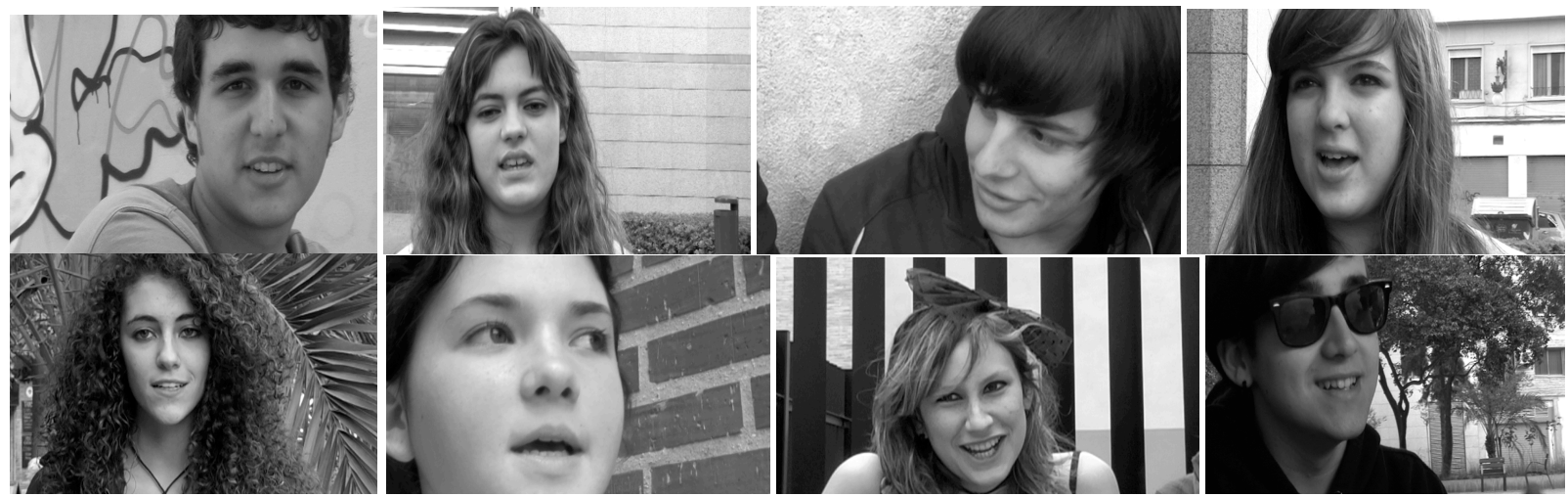

Fotogramas del video Nosotr@s hablamos. Algun@s protagonistas de las entrevistas en en el audiovisual

Nuestra creación audiovisual se decanta hacia la entrevista como metodología participativa y es por este motivo que hemos planteado un epílogo constituido únicamente por testimonios de $@$ @ adolescentes que se presenta a modo de reflexión, partiendo de los discursos directos y motivados por la pregunta: "¿existe igualdad real en nuestra sociedad?". Se trata aquí de ofrecer un marco de debate para visibilizar las discriminaciones y fomentar la exploración de nuevos modelos culturales de actuación y relación que favorezcan la igualdad, pero también de ofrecer una visión de empoderamiento, dinamizadora y positiva acerca de la posibilidad de alcanzar la igualdad en nuestra sociedad occidental a través del debate, la escucha, la reflexión y la motivación hacia el cambio del modo de pensamiento único, patriarcal y dominante.

\section{CONCLUSIONES}

Como conclusión general, el material audiovisual Nosotr@s hablamos plantea el importante espacio que ocupan las relaciones interpersonales en el desarrollo humano y, en particular en la adolescencia, las relaciones de amistad y amor. Las personas, a partir de las matrices de relación social establecidas, configuramos roles que estructuran nuestra identidad y posibilitan un desarrollo de nuestras potencialidades y capacidad de participar de forma activa en la sociedad, es decir, de individuarnos y ocupar espacios de ciudadanía. Será a través del proceso de socialización como se adquieran las prescripciones relativas a nuestra condición sexuada que, además de permitirnos internalizar el "deber ser" social, en una sociedad androcéntrica como la nuestra, nos aporte herramientas para actuar "de manera adecuada" con esos valores en la vida adulta.

En el vídeo se sugiere cómo la socialización de género nos construye y desarrolla parcialmente a ambos sexos. Se expone cómo el imaginario masculino estereotipado, lamentablemente aún vigente, se fundamenta en la autoafirmación, el hiperdesarrollo del yo exterior, la orientación al dominio y al control, la competitividad y consecución de logros, la inexpresividad y autocontrol emocional; 
es decir, aboga por un sujeto autónomo, fuerte e independiente, sustentado en mitos en torno a una virilidad asertiva y dominante, que debe ser permanentemente afirmada, a través de la demostración de autoridad en la familia, en la pareja, en los espacios de relación interpersonal en general y, en algunos casos, incluso a través de la violencia. En suma, una masculinidad que resulta de la interiorización del sexismo como afirmación de poder y como negación o rechazo de la feminidad, que se expresa también en forma de homofobia.

En concreto, en el imaginario cultural el ideal de feminidad se representa por la preocupación por el bienestar de l@s otr@s y una autoestima vinculada a la armonía del grupo, por una expresividad emocional y maternalizada con dependencia de la pareja (sobre la que pesa el estigma de la soledad), en definitiva, por una objetualización donde el cuerpo y el propio deseo se hallan a merced de la mirada del otro. La estereotipia femenina representa a la mujer como un sujeto emotivo, sensible y dependiente, sustentado en mitos en torno al poder del amor romántico, que enfatiza una mística de la abnegación y fomenta un intercambio de "protección por obediencia" que refuerza posiciones de dependencia y sumisión; tener valor en relación al otro, vivir para l@s otr@s, enfrenta a las mujeres a la propia devaluación y a la carencia o retraso de su proyecto vital, desde una interiorización del sexismo que se expresa a través de estrategias emocionales que no hacen sino confirmar la dependencia de la protección y autoridad del varón. A pesar de los muchos avances en la toma de conciencia de igualdad, en capacidad y en derechos, se constata que, en cuestiones relativas al reconocimiento en las relaciones entre sexos, fundamentalmente en el ámbito afectivo, siguen quedando residuos que favorecen posiciones de subordinación que "demandan" solapadamente la aprobación de la pareja o de los chicos del grupo. La socialización generizada favorece posiciones desiguales que sustentan relaciones asimétricas de poder entre sexos y son germen de la violencia de género.

El epílogo. superando discriminaciones se plantea como resumen y como conclusión abierta a partir de la reflexión de los y las adolescentes, que invita a continuar el debate en torno a la posibilidad de construir una igualdad real, basada en la superación de discriminaciones que se sostienen en mitos y modelos educativos. La creencia compartida de una igualdad entre sexos se ve cuestionada y deconstruida, desde la necesidad de hacer visibles las discriminaciones y de proponer nuevos modelos de actuación y relación. Es necesario que chicos y chicas conozcan sus propias capacidades, expectativas, valores, deseos... y demanden reconocimiento y respeto hacia la propia persona como base para el desarrollo de la propia subjetividad. Los testimonios finales pretenden estimular un debate crítico, fundamentado en el respeto mutuo, en el que se pregunten acerca de sus prácticas cotidianas para desvelar los elementos que contribuyen a perpetuar el sexismo en nuestra cultura. Satisfacer las propias ideas y necesidades y poder tomar decisiones, relacionarse libremente con el propio cuerpo, saberse sujeto de derechos, exige un plus de esfuerzo considerable, pero vale la pena porque si no se sabe qué se desea, es fácil sucumbir al deseo de los demás.

Podemos concluir, a partir de esta experiencia audiovisual basada en la video-creación, los estudios feministas de enero, la psicología, la sociología, la pedagogía y el arte, que la interdisciplinariedad así como la capacidad emancipatoria del análisis y la praxis feminista, son la base fundamental para el éxito en un planteamiento alternativo y de apoyo a la deconstrucción de la ideología machista dominante, ya que fomenta una pedagogía de la imagen capaz de superar la violencia de género estructural y simbólica que subyacen a nuestra sociedad. Además, es necesaria y acuciante la inserción social de estos contenidos alternativos, ya que suponen actos de resistencia y acciones necesarias en la tarea de divulgación, educación y formación en la igualdad frente a la desigualdad de género reflejada en los medios de masas y en la propia realidad social. Por último, el proyecto Nosotr@s hablamos nos demuestra que hoy, más que nunca, es necesaria la reivindicación de la presencia de la mujer no sólo como usuaria de tecnología sino, de manera especial, como participante activa en las políticas de producción y distribución del material audiovisual y en las políticas sociales y educativas vinculadas a la tecnología, ya que los medios de masas en general, representan y están dominados por la cultura dominante que es la del patriarcado.

\section{FUENTES REFERENCIALES}

ALTABLE, Ch. Penélope o las trampas del amor. Valencia: Nau Llibres, 1999.

BECK, U., y BECK-GERNSHEIM, E. El normal caos del amor. Las nuevas formas de relación amorosa. Barcelona: Paidós, 2001. Orig. inglés 1998.

BEVERLEY, J. La persistencia del subalterno. Revista Iberoamericana, 203, 2003, pp. 335-342.

BONILLA, A. Género, identidades y violencia. En I. MARTíNEZ BENLLOCH et al., Imaginario cultural, construcción de identidades de género y violencia: formación para la igualdad en la adolescencia (pp. 15-34). Madrid: Instituto de la Mujer (Colección Estudios, 103), 2008.

BOURDIEU, P. Meditaciones pascalianas. Barcelona: Anagrama, 1997.

BOURDIEU, P. La dominación masculina. Barcelona: Anagrama, 2000. 
BRENNER, J.B. Y CUNNINGHAM, J.G. Gender differences in eating attitudes, body concept, and self-esteem among models. Sex Roles, 27, 1992, pp. 413-437.

BURIN, M. Ámbito familiar y construcción del género. En M. Burin e I. Meler, Género y familia. Poder, amor y sexualidad en la construcción de la subjetividad (pp. 71-86). Buenos Aires: Paidós, 1998.

BURMAN, E. La Deconstrucción de la Psicología Evolutiva. Madrid: Visor, 1994.

CORTÉS, J.M. Hombres de mármol. Madrid: Egales, 2004.

FOUCAULT, M. Historia de la sexualidad. Vol. 1: La voluntad de saber. Madrid: Siglo XXI, 1978. Orig. francés, 1976.

FRABLE, D.E.S. Gender, racial, ethnic, sexual and class identities. Annual Review of Psychology, 48, 1997, pp. $139-162$.

FULLER, N. La constitución social de la identidad de género entre varones urbanos del Perú. In: VALDÉS, Teresa y OLAVARIA, José (eds.). Masculinidades y equidad de género en América Latina. Santiago de Chile: FLACSO, 1998, pp. 56-69.

GALENDE, E. De un horizonte incierto. Psicoanálisis y salud mental en la sociedad actual. Barcelona. Paidós, 1997.

GIBERTI. E y FERNANDEZ. A. La mujer y la violencia invisible. Buenos Aires: Sudamericana, 1989.

LAGARDE, M. Género y feminismo: Desarrollo humano y democracia. Madrid: Horas y Horas, 1996.

LAGARDE, M. Para mis socias de la vida. Madrid: Horas y Horas, 2005.

LAMAS, M. Cuerpo e identidad. En L.G. Arango, M. León y M. Viveros (comps.), Género e Identidad. Ensayos sobre lo femenino y lo masculino. Bogotá: Tercer Mundo Editores, 1995.

LAMAS, M. Problemas sociales causados por el género, 1996. Disponible en: http://www.hombresigualdad.com/problemassocialesmarta.htm.

LAMAS, M. Cuerpo, diferencia sexual y género. México: Taurus, 2000.

LAMEIRAS, M. El sexismo y sus dos caras: De la hostilidad a la ambivalencia. Anuario de Sexología, 8, 2002, pp. 91-102.

MARTÍNEZ BENLLOCH, I. Cuerpo, sexualidad y amor. In MARTÍNEZ BENLLOCH, I. et al., Imaginario cultural, construcción de identidades de género y violencia: formación para la igualdad en la adolescencia (pp. 88-112). Madrid: Instituto de la Mujer (Colección Estudios, 103), 2008.

MARTÍNEZ BENLLOCH, I. y BONILLA, A. Sistema sexo/género, identidades y construcción de la subjetividad. Valencia: Publicacions de la Universitat de Vàlencia, 2000.

OSBORNE, R. La construcción sexual de la realidad: un debate en la sociología contemporánea de la mujer. Madrid: Cátedra, 1993.

PASTOR, R. Cuerpo y género: representación e imagen corporal. In BARBERÁ, E. e MARTínEZ BENLLOCH, I. (coords), Psicología y Género (pp. 218-239). Madrid: Pearson. Prentice-Hall, 2004.

RODRÍGUEZ, Z. Paradojas del amor romántico. México: Instituto Mexicano de la Juventud, 2006.

RUBIN, G. El tráfico de las mujeres: notas sobre la "economía política del sexo". Nueva Antropología, 30, Noviembre 1986, pp. 95-145.

TUBERT, S. Identidad y adolescencia. Reflexiones sobre un mito. Clínica y Salud, VIII, 2, 1997.

TUBERT, S. Deseo y representación. Madrid: Síntesis, 2001.

TUBERT, S. La construcción de la identidad sexuada en la adolescencia. En I. Martínez Benlloch et al., Imaginario cultural, construcción de identidades de género y violencia: formación para la igualdad en la adolescencia. (pp. 50-87). Madrid: Instituto de la Mujer (Colección Estudios, 103), 2008.

VANCE, C.S. Placer y peligro. Explorando la sexualidad femenina. Madrid: Revolución S.A, 1989. Orig. inglés 1984.

VEGA, C. Situarnos en la historia. Movimiento feminista y políticas contra la violencia en el Estado Español. In VILLAPLANA, V. y SICHEL, B. (coords), Relatos culturales en torno a la violencia de género. Madrid: Dpto. Audiovisuales del MNCARS, 2005.

VILLAPLANA, V. y SICHEL, B. (coords) Relatos culturales en torno a la violencia de género. Madrid: Dpto. Audiovisuales del MNCARS, 2005.

WALTER, N. Muñecas vivientes. El regreso del sexismo. Madrid: Turner Publicaciones, 2010.

WEEKS, J. La construcción cultural de las sexualidades. ¿Qué queremos decir cuando hablamos de cuerpo y sexualidad? En I. Szasz y S.Lerner (comps.), Sexualidades en México. Algunas aproximaciones desde la perspectiva de las ciencias sociales (pp. 199-221). México: El Colegio de México, 1998.

YOUNG, I. M. La justicia y la política de la diferencia. Madrid: Cátedra, 1990. 
- Programa "Corta con los malos rollos", de la Generalitat de Catalunya: http://www.gencat.cat/icdones/tmr/esp/modul1tema2.html Campaña "Talla amb els mals rotllos": http://www.youtube.com/watch?v=JIJOrGumjQI\&feature=related http://www.youtube.com/watch?v=RnUvqbBJdG4\&NR=1 http://www.youtube.com/watch?v=_3qUMkISCmQ\&NR=1

- Programa de educación afectivo-sexual "Ni ogros ni princesas", del Gobierno del Principado de Asturias: http://www.educastur.es/index.php?option=com_content\&task=view\&id=821\&ltemid=75

- Dona m un minut: Laboratorio de nuevas representaciones sobre violencia machista (Candela, asociación para la prevención de las violencias de género): http://candela.pimienta.org/5.html

- Dove evolution: La manipulación de la belleza: http://www.dove.ca/en/default.aspx\#/features/videos/video_gallery.aspx[cp-documentid=9150778]

- Relaciones de pareja en adolescencia y violencia de género (Red Extremeña contra la Violencia de Género): http://www.rednoviolenciagex.com/index.php?option=com_content\&view=article\&id=232:adolescentes-hablan-de-lasrelaciones-de-pareja-y-violencia-de-genero-\&catid=17:videos\&ltemid=18.

- “Amores que matan" (Icíar Bollaín, 2000). Actividad didáctica: http://www.nodo50.org/filosofem/spip.php?article60

- Actividades de coeducación: Violencia entre parejas adolescentes (IES Ben Gabirol, Málaga): http://www.slideshare.net/coeducacionbg/violencia-entre-parejas-adolescentes-presentation Actividades contra la violencia y por los buenos tratos (IES Azahar, Sevilla): http://www.youtube.com/watch?v=7KDyj7JmUg8 Prevención de la violencia de género (IES Camp de Túria, Lliria, Valencia): http://www.youtube.com/watch?v=716rhrAEOpl

- Campañas contra la violencia de género: http://www.youtube.com/watch?v=rqko11r21Nw\&feature=related http://www.youtube.com/watch?v=956eZZF5ZwU\&feature=related http://www.youtube.com/watch?v=4yOoRwKzObk\&fe http://www.youtube.com/watch?v=PvDMbwbSu9c\&feature=fvwrel http://www.youtube.com/watch?v=wpgV53UpJSY\&feature=related http://www.youtube.com/watch?v=yYG1G5PrfNQ\&feature=related http://www.youtube.com/watch?v=kalehqska2k\&feature=related

- Prevenir la violencia: una cuestión de cambio de actitud (Instituto de la Mujer, 2000): http://www.observatoriodegenero.org/?q=node/107

- Materiales para prevenir la violencia contra las mujeres desde el marco educativo. Unidad didáctica para Educación Secundaria (Instituto de la Mujer de la Región de Murcia, 2005): http://www.femiteca.com/IMG/pdf_violencia.pdf

- Prevenir la violencia contra las mujeres: construyendo la igualdad. Programa para secundaria (Instituto de la Mujer, 2002): http://www.inmujer.migualdad.es/mujer/publicaciones/docs/09prevenir.pdf

- Materiales Didácticos para la Prevención de la Violencia de Género (Junta de Andalucía): Educación Secundaria: http://www.bvsde.paho.org/bvsacd/cd59/materiales.pdf Educación de Personas Adultas: http://www.bvsde.paho.org/bvsacd/cd26/genero_adultas.pdf http://www.juntadeandalucia.es/averroes/ cepal2/moodle/mod/resource/view.php?inpopup=true\&id=5645 